\title{
Low-Cost Computing Using Raspberry Pi 2 Model B
}

\author{
Ar Kar Kyaw ${ }^{1,2 *}$, Hong Phat Truong3, Justin Joseph ${ }^{2}$ \\ ${ }^{1}$ Digital Forensic Research Labs, Auckland University of Technology, Auckland, New Zealand. \\ ${ }^{2}$ Whitireia Community Polytechnic, 450 Queen Street, Auckland, New Zealand. \\ ${ }^{3}$ Super Shuttle, Auckland, New Zealand. \\ * Corresponding author. Email: arkar.kyaw@whitireia.ac.nz \\ Manuscript submitted March 1, 2017; accepted June 21, 2017. \\ doi: 10.17706/jcp.13.3.287-299
}

\begin{abstract}
A low-cost computing environment using Raspberry Pi based systems is very efficient to use as a proposed computing system in libraries and classrooms of schools in the developing countries such as Argentina, Bangladesh, Cambodia, China, Kiribati, Myanmar, Tuvalu, Vietnam and Zimbabwe where money is always a constraint. This paper presents the results of an experimental set up of the low-cost computing environment using Raspberry Pi 2 (Model B), a cost-benefit analysis and a discussion of findings in addition to a literature review about Raspberry Pi and a methodology that is applied.
\end{abstract}

Key words: Low-cost computing, LCC, raspberry Pi 2 model B, cost-benefit analysis.

\section{Introduction}

To improve the educational levels of learners in developing countries, it is important to implement a computing environment that is affordable and durable. Raspberry Pi is a multi-purpose low-cost Advanced Reduced-Instruction-Set-Computer (ARM) processor-based miniature device that has been utilised as a standalone machine in schools to improve the education provision in rural areas [1]-[3]. A network-based low-cost computing (LCC) environment is designed and implemented by using Raspberry Pi 2 Model B devices in this research project. Usability testing of the implemented system is conducted by participants before collecting data using an online questionnaire. Subsequently, the collected data is analysed and a cost-benefit analysis is discussed. With this implemented prototype system, students from schools where the computing budget is a constraint (especially in developing countries) can have the opportunity to access to educational resources.

This paper outlines the results of research into the test-bed setup of low-cost computing environment using Raspberry Pi 2. Section 2 contains a review of literature, including related previous work. Section 3 outlines the methodology including the research questions. Section 4 contains the findings - analysis of collected data from a pilot test and a Cost-Benefit Analysis (CBA) of the provisioning of LCC environments. Section 5 presents a discussion that is followed by conclusion and future work (Section 6).

\section{Literature Review}

A review of the literature provided in this section includes a brief overview of Raspberry Pi, a review of previously published articles and contributions of our research.

\subsection{Raspberry Pi}

Raspberry Pi is a card-sized minicomputer that can either operate on mains or battery power. Raspbian is 
a provided operating system (OS), but there are various other ARM-Linux OS variants that can run on it. This miniature device can be used for robotics, arcade machines, and temperature probing devices. It can also be used for MATLAB applications, among others, and comes in a variety of models with different interfaces for different requirements. Raspberry Pi 2 Model B (the latest version of the hardware as of November 2015) has 1 gigabyte (GB) of random access memory (RAM), a 900MHz quad-core ARM processor, four universal serial bus (USB) interfaces, an Ethernet port, a mini USB for power supply and high-definition multimedia interface (HDMI) for display. The OS is flashed onto a micro Secure Digital (SD) card [4]. The running device can either be accessed directly using a USB keyboard, mouse and display or via a LAN port by creating a secure shell (SSH) session remotely.

\subsection{Previous Related Work}

Table 1. Review of Previous Published Articles

\begin{tabular}{|c|c|}
\hline Author(s) & Contributions \\
\hline Agrawal \& Singhal [5] & $\begin{array}{l}\text { - Researchers discussed a smart drip irrigation system using Raspberry Pi including a proposed } \\
\text { design for a home automation system, energy efficient devices, including Raspberry Pi, Arduino } \\
\text { microcontrollers, XBee modules and relay boards. } \\
\text { - These energy efficient devices were used due to low cost. }\end{array}$ \\
\hline $\begin{array}{l}\text { Danymol, Ajitha \& } \\
\text { Gandhiraj [6] }\end{array}$ & $\begin{array}{l}\text { - Researchers explained about real time communication systems and the use of Raspberry Pi } \\
\text { because it is cheap and small. }\end{array}$ \\
\hline Lynn [1] & $\begin{array}{l}\text { - Lynn discussed about two researchers, Bock and Jalia from Cambridge University, who } \\
\text { conducted "a pilot project exploring possibilities of providing computing access and education } \\
\text { in rural schools in India (p. 1)" by using Raspberry Pi. } \\
\text { - The main idea of using Raspberry Pi was getting students engaged in computing and learning to } \\
\text { program. } \\
\text { - However, Raspberry Pi was used as a standalone computer to compose music, drawings and } \\
\text { build robots. }\end{array}$ \\
\hline Slaven [2] & $\begin{array}{l}\text { - Slaven explained about the "development of an offline server, named 'RACHEL", which was not } \\
\text { connected to the internet. } \\
\text { - Raspberry Pi was used as a means of improving education provision in rural areas. } \\
\text { - } 25 \text { Raspberry Pi's were installed in schools to be used in Cameroon to the power generator to } \\
\text { give possibilities to their students and teachers to learn spreadsheet and word processing. } \\
\text { - Slaven also discussed that two researchers, Bock and Jalia, from Cambridge University who } \\
\text { introduced Raspberry Pi in Ecuador as "part of their long-term plan to ensure the sustainability } \\
\text { of using Raspberry Pi based education content". }\end{array}$ \\
\hline $\begin{array}{c}\text { Severance \& } \\
\text { Fontichiaro [3] }\end{array}$ & $\begin{array}{l}\text { - Researchers discussed the history of Raspberry Pi's development and potential applications of } \\
\text { Pi in classrooms for engaging students in programming. }\end{array}$ \\
\hline $\begin{array}{l}\text { Kyuchukova, Hristov, } \\
\text { Zahariev, \& Borisov [7] }\end{array}$ & $\begin{array}{l}\text { - Researchers discussed the possibility of using Raspberry Pi as a console server for remote } \\
\text { access to devices in Virtual Learning Environments (VLE). } \\
\text { - They also outlined the designing, planning and creation of a virtual laboratory. }\end{array}$ \\
\hline $\begin{array}{l}\text { Srinivasan, Anand, } \\
\text { Antony Venus, Victor, } \\
\text { Narayanan, Sree } \\
\text { Rakshaa [8] }\end{array}$ & $\begin{array}{l}\text { - Researchers explained about the combinations of technologies to facilitate education in rural } \\
\text { India by using Raspberry Pi devices. }\end{array}$ \\
\hline $\begin{array}{l}\text { Soetedjo, Ashari, } \\
\text { Mahmudi, Nakhoda [9] }\end{array}$ & $\begin{array}{l}\text { - Researchers discussed the application of Raspberry Pi for detecting laser spot using the } \\
\text { OpenCV library. }\end{array}$ \\
\hline $\begin{array}{l}\text { Byrne, Fisher \& } \\
\text { Tangney [10] }\end{array}$ & $\begin{array}{l}\text { - Researchers explained about Raspberry Pi in the 21st-century learning environment and } \\
\text { adaption of a Bridge21 model for Raspberry Pi. } \\
\text { - Raspberry Pi was used to introduce basic code compilation. }\end{array}$ \\
\hline $\begin{array}{l}\text { Fung, White, Jouet, } \\
\text { Singer \& Pezaros [11] }\end{array}$ & $\begin{array}{l}\text { - Researchers discussed Glasgow Raspberry Pi cloud and Pi cloud for resource management in } \\
\text { cloud computing. }\end{array}$ \\
\hline $\begin{array}{l}\text { Kaup, Gottschling \& } \\
\text { Hausheer [12] }\end{array}$ & $\begin{array}{l}\text { - Researchers explained about a power consumption model for the Raspberry Pi, which was } \\
\text { used as a substitute to conventional home gateways to derive the impact of typical hardware } \\
\text { components on the energy consumption. }\end{array}$ \\
\hline
\end{tabular}




\begin{tabular}{|c|c|}
\hline Author(s) & Contributions \\
\hline & $\bullet$ Raspberry Pi was used because of low power consumption. \\
\hline
\end{tabular}

According to previous literature, researchers utilized Raspberry Pi in different ways and their contributions are summarised in the following table.

\subsection{Our Contributions}

Our main contribution in this research was to utilize and demonstrate the usage of Raspberry Pi 2 Model B devices as client computers in a proposed internet-connected LCC environment. It is envisaged that this LCC environment can be deployed in libraries or classroom environments in developing countries.

\section{Methodology}

A literature review was conducted to identify previous work in the general and experimental usage of Raspberry Pi and similar low-cost devices. After conducting a literature review, a suitable mixed-method of experimental and survey methodology was crafted to fit the aims of this project - to create and test a test-bed LCC environment. The experimental method was used to design and implement the low-cost computing [13], [14] and then the survey methodology was used for conducting a pilot test with participants, who had hands-on experience using the LCC environment prior to completing an online questionnaire survey [15]. A total of 87 participants were invited to take part in the pilot testing, 22 students and 65 staff, but only 38 out of 87 invitees participated in the pilot testing of the low-cost computing.

\subsection{Research Question}

The LCC research project was attempting to find answers to three key questions. The questions were:

Q1. What software and hardware are required to set up low-cost computing (LCC) for libraries and classrooms?

Q2. Is a Raspberry Pi based client a suitable replacement for the computer in the libraries and classrooms in developing countries?

Q3. What are the benefits of the proposed LCC system?

\subsection{Final Research Phases}

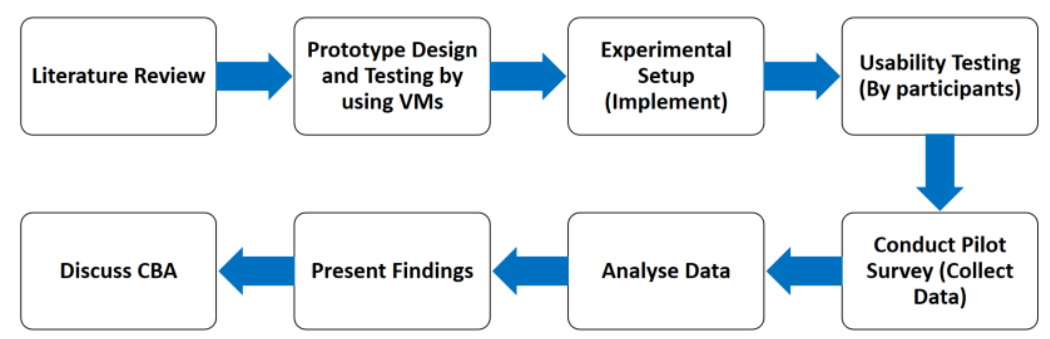

Fig. 1. Research phases.

To answer these research questions (Section 3.1) it was necessary to follow a pre-defined methodology, with distinct phases (Fig. 1), in order to setup and evaluate the test-bed environment (as the LCC prototype) consisting of computer servers and multiple Raspberry Pi devices as client (end-user) computers.

\subsection{Experimental Setup}

The LCC network architecture (Fig. 2) includes three virtual local area networks (VLANs), three physical servers, four virtualized servers, two Raspberry Pi clients and one pfSense gateway computer that are connected to a Cisco Catalyst 2950 switch. 
The test-bed prototype implementation design has three VLANs - VLAN1 for servers, VLAN20 for production network (classrooms \& office) and VLAN 30 for the library. VLANs are used to create network segments using managed switches to isolate network users and devices - as an added security measure. Using VLANs in a network does require managed switches, but cost more than unmanaged switches and add network management overhead. VLANs can be omitted from the design resulting in a non-complex, non-hierarchical design if the expertise does not exist to manage the network.

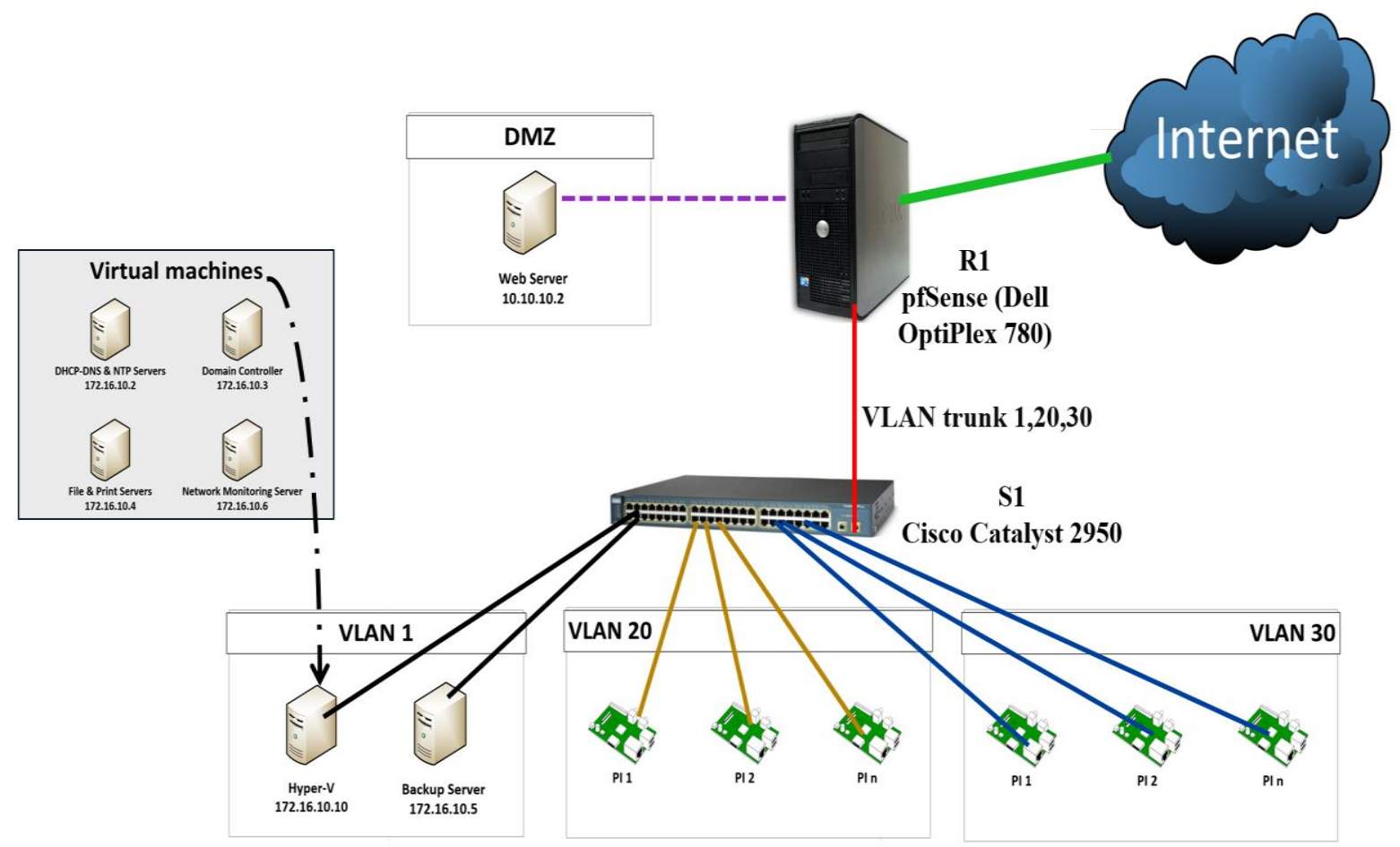

Fig. 2. System architecture for the experiment.

The three physical computer servers are Backup server (utilizing Bacula network backup software), Virtualization server (utilizing Microsoft Hyper-V) and Web server (utilizing XAMPP web application hosting software). The four virtualized servers provision core network services: directory (authentication), DNS, DHCP, file sharing, printing and network monitoring. The client and server OSes, application and network services software are presented in Tables 6, 7, 8 and 9 (see Appendix).

\subsection{Data Collection}

The pilot testing and survey method were used for data collection [4]. The following questions were used in an online survey as part of the data collection process.

- How often do you use computers in the library?

- What is the main purpose of using computers in the library?

- How familiar are you with computers?

- How was your web browsing experience on Raspberry Pi-based system?

- How was your experience using LibreOffice application on Raspberry Pi-based system?

- How was your experience using file sharing and printing services on Raspberry Pi-based system?

- Is the Raspberry Pi-based computer a suitable replacement for computers in the libraries?

- Can you suggest ways to improve Raspberry Pi-based LCC system?

Before inviting Whitireia New Zealand students and staff (academic and administration) from different faculties and departments to take part in pilot testing and completing an online survey on their experience as 
an end-user, a trial test was conducted with three student participants. The survey questions were refined from the provided feedback. Thereafter, final pilot testing and online survey were conducted. The collected data was processed, analysed and presented in tables and charts (refer to Section 4).

To electronically collect data, a questionnaire was uploaded to a free online survey engine - Google Forms. The staff were invited by email, while students were randomly approached on campus to take part in this research.

\section{Findings and CBA}

This section presents the collated findings of the survey completed by the participants who tested the proposed LCC environment and then presents a Cost Benefit Analysis (CBA) of implementing it.

\subsection{Data Collection}

A total of 38 participants (22 students and 65 staff were invited) took part in the pilot testing and afterwards completed the online survey. The major findings are depicted in the following figures (Fig. 3, 4, 5, 6, 7 and 8).

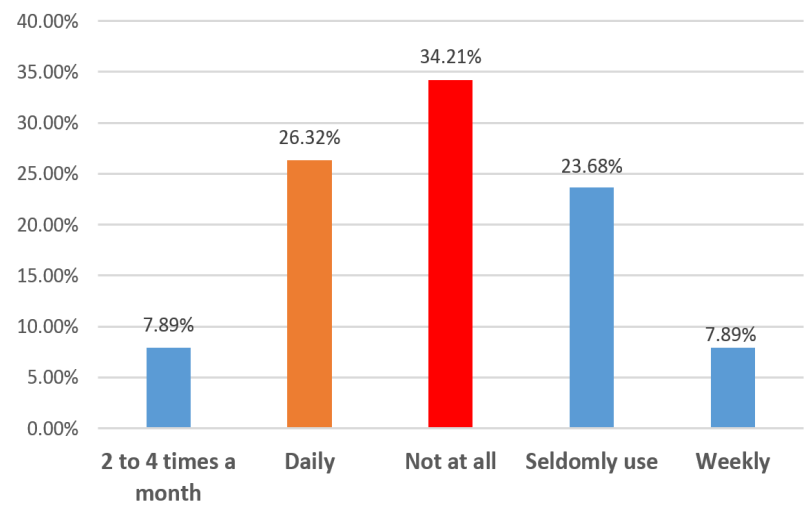

Fig. 3. Frequency of using computers in library.

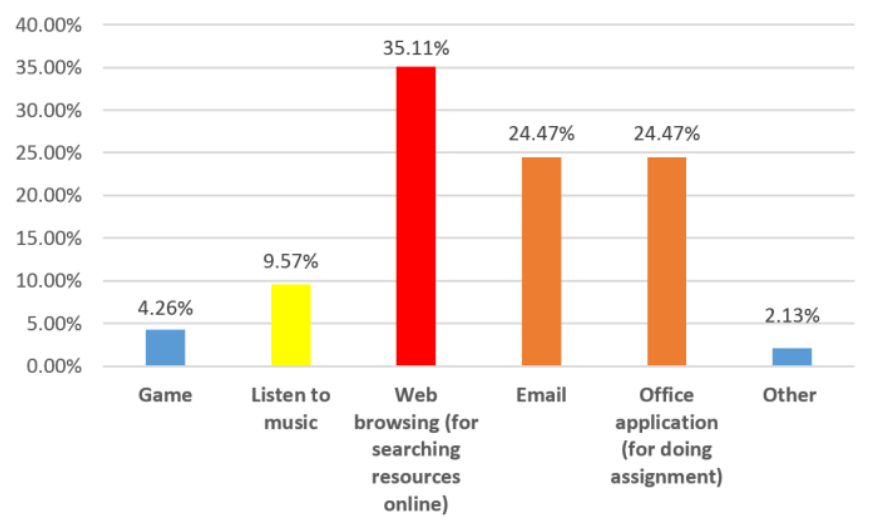

Fig. 4. Purpose of using computers in library.

Over $34 \%$ of participants had not used the computers in the library at all, but $26 \%$ used it on a daily basis (Fig. 3). Approximately 35\% of participants use library computer for web browsing whereas $49 \%$ use it for emails and using Office productivity software for doing assignments, etc., (Fig. 4).

Similarly, $55 \%$ of participants were expert to very familiar with web browsing while $32 \%$ were fairly familiar to familiar in using Google Chrome and Mozilla Firefox (Fig. 5). Both these browsers were installed on the LCC Raspberry Pi 2 client computer. 


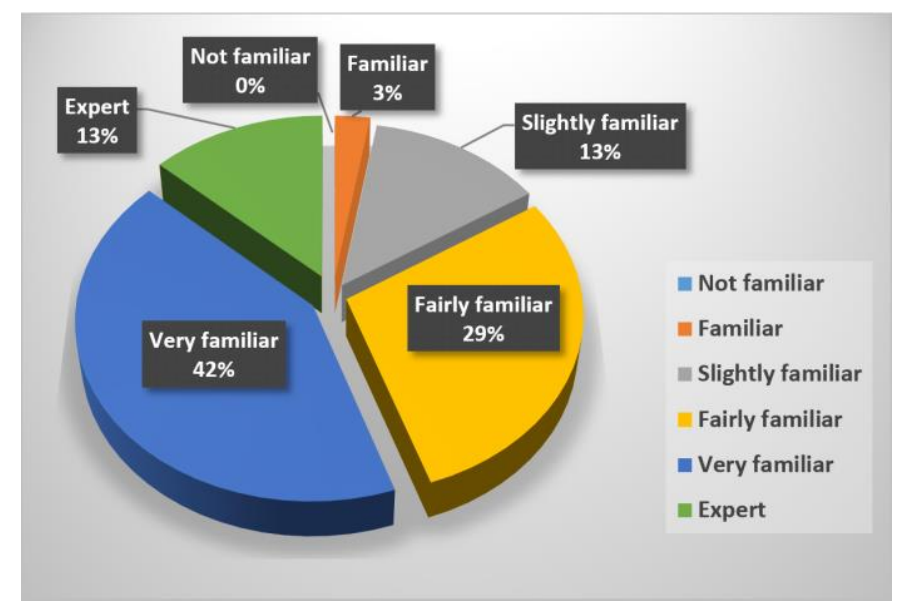

Fig. 5. Participants' experience in using web browsing.

Likewise, $44 \%$ of participants were expert to very familiar while $36 \%$ were fairly familiar to familiar in using LibreOffice Suite on the LCC Raspberry Pi 2 client computer (Fig. 6).

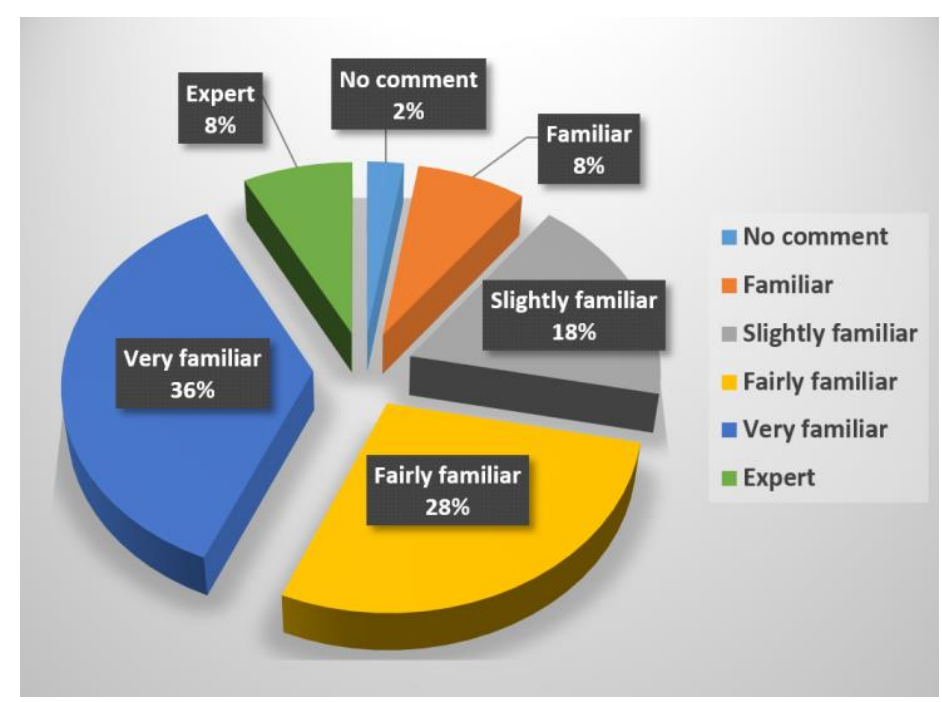

Fig. 6. Participants' experience in using the open source LibreOffice Suite on Raspberry Pi 2.

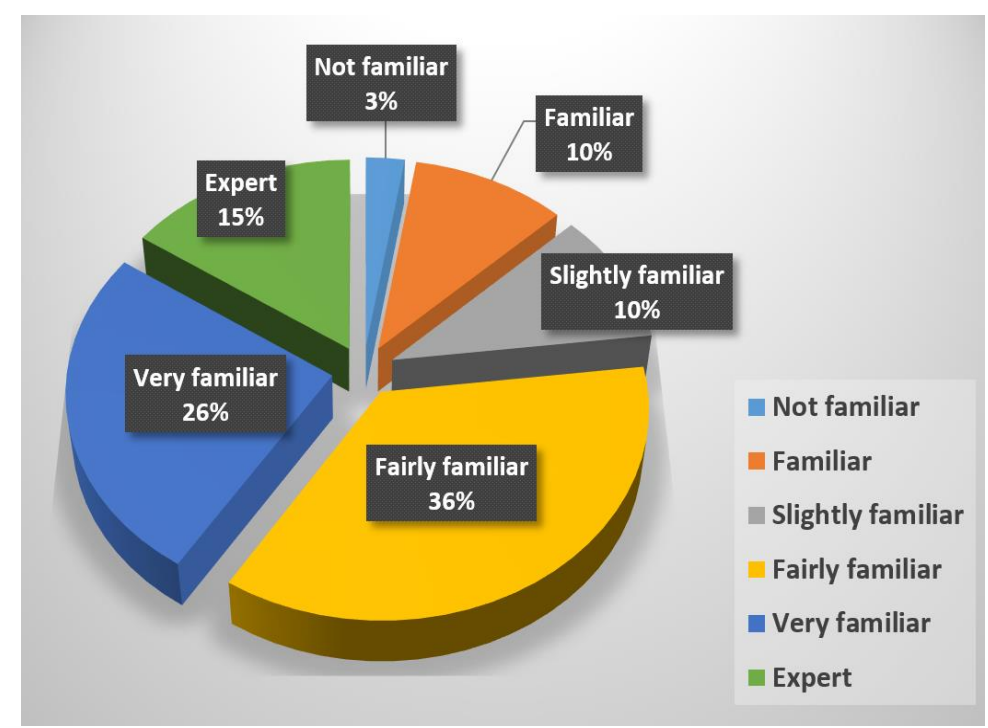

Fig. 7. Participants' experience in using file sharing and printing on Raspberry Pi 2. 
In using file sharing and printing services available on the LCC Raspberry Pi 2 client computer, $41 \%$ of participants were expert to very familiar while $46 \%$ were fairly familiar to familiar (Fig. 7). That Raspberry Pi 2 based LCC system was a suitable replacement for PCs in libraries, 87\% of participants agreed while 13\% disagreed (Fig. 8).

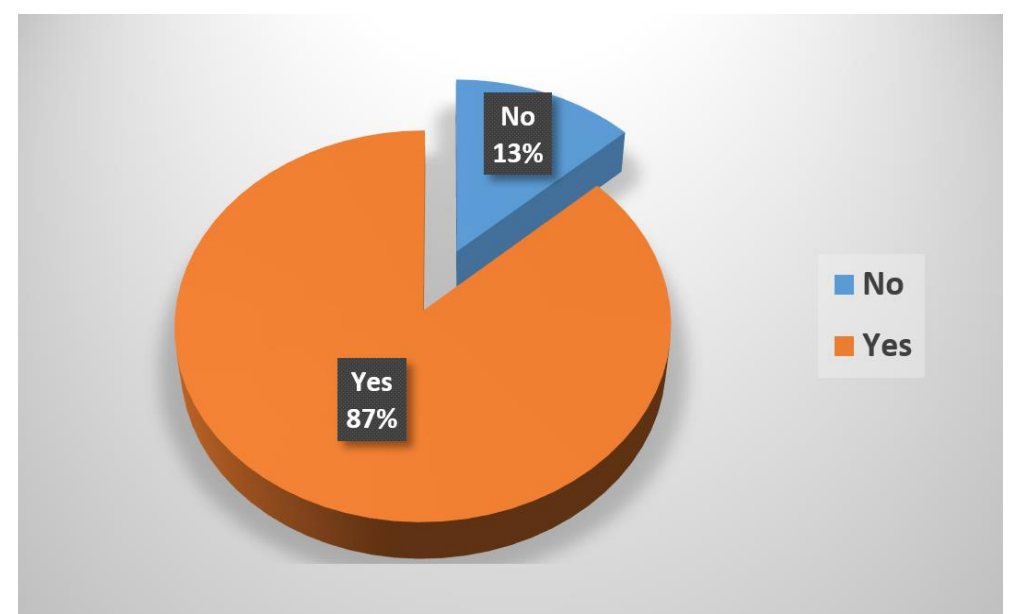

Fig. 8. Participants' answers to whether or not Raspberry Pi 2 based clients are suitable replacements for PCs in libraries.

Based on the results of this pilot testing and survey, the participants also suggested that user training could be a way of improving the user's knowledge of using this system. The results of this research also highlighted that the majority of participants had their own computers for their own personal needs.

\subsection{Cost-Benefit Analysis}

The purpose of the cost-benefit analysis (CBA) is to determine whether the proposed LCC environment is a viable option for libraries and classrooms in developing countries.

CBA has two purposes, which are:

- Determining if the proposed LCC environment is a feasible investment or decision (i.e., a justification of feasibility or advantage), and

- Comparing the total expected cost of each alternative against the total benefits.

Calculating a cost-benefit analysis does provide the cost and benefits that will be helpful in analysing and evaluating the three alternative system approaches.

There are three alternative approaches in the CBA calculations:

- Existing system refers to the existing computing environment in the library of Whitireia (Auckland Campus).

- Proposed refers to the proposed low-cost computing environment for libraries and classrooms for developing countries.

- Assumed system refers to a computing environment that can be set up by using second-hand personal computers (PCs) where an organisation or a school cannot afford to buy new PCs.

The costings of all three systems were considered as alternatives in determining a viable LCC solution.

The CBA takes into consideration the expected costs in setting up a LCC environment for school libraries that include twenty PCs (including both one-time and recurring costs). The calculation of expected costs is based on the formula provided by the researchers [16]. Cost elements such as operational costs, human resource cost, power consumption, individual system (client PC and server) and software costs are factored into the CBA calculations [17]. 
Table 2 presents the total cost of the setup of each system (server and client). The cost of each factor includes hardware, software, human resources and power consumption for all three alternatives of the existing, proposed and assumed systems including server and client [16]-[18].

Table 3 presents the individual cost of hardware and software required for setting up a client and server environment. It also displays the total costs of hardware and software for the client as well as hardware and software for server systems.

Table 2. Hardware and Software Costs for Server and Client [17]-[19]

\begin{tabular}{|l|c|c|c|}
\hline Cost Factors (NZ\$) & $\begin{array}{c}\text { Existing System } \\
\text { (HP EliteDesk 800 G1 DM) }\end{array}$ & $\begin{array}{c}\text { Assumed System } \\
\text { (Dell OptiPlex 780) }\end{array}$ & $\begin{array}{c}\text { Proposed System } \\
\text { (Raspberry Pi 2 Model B) }\end{array}$ \\
\hline Server Hardware & & & \\
\hline Keyboard / Mouse & $\$ 30.00$ & $\$ 10.00$ & $\$ 10.00$ \\
\hline Dell PowerEdge R730xd & $\$ 3,720.00$ & $\$ 3,720.00$ & $\$ 3,720.00$ \\
\hline Server Software & & & $\$ 0.00$ \\
\hline Microsoft (MS) Windows Server 2012R2 & $\$ 9,137.47$ & $\$ 0.00$ & $\$ 0.00$ \\
\hline MS System Center 2012 & $\$ 5,354.81$ & $\$ 0.00$ & $\$ \mathbf{3 3 , 7 3 0 . 0 0}$ \\
\hline $\begin{array}{l}\text { Total Cost of the Main Server } \\
\text { System (approximately) }\end{array}$ & $\mathbf{\$ 1 8 , 2 4 2 . 2 8}$ & $\mathbf{\$ 3 , 7 3 0 . 0 0}$ & \\
\hline
\end{tabular}

\begin{tabular}{|l|c|c|c|}
\hline Cost Factors (NZ\$) & $\begin{array}{c}\text { Existing System } \\
\text { (HP EliteDesk 800 G1 DM) }\end{array}$ & $\begin{array}{c}\text { Assumed System } \\
\text { (Dell OptiPlex 780) }\end{array}$ & $\begin{array}{c}\text { Proposed System } \\
\text { (Raspberry Pi 2 Model B) }\end{array}$ \\
\hline Client Hardware & & & \\
\hline Keyboard / Mouse & $\$ 30.00$ & $\$ 10.00$ & $\$ 10.00$ \\
\hline System unit \& monitor & $\$ 1,500.00$ & $\$ 355.20$ & $\$ 134.20$ \\
\hline Client Software & $\$ 296.91$ & $\$ 296.91$ & $\$ 0.00$ \\
\hline MS Windows 10 & $\$ 742.28$ & $\$ 742.28$ & $\$ 0.00$ \\
\hline MS Office 2016 & $\mathbf{\$ 2 , 5 6 9 . 1 9}$ & $\mathbf{\$ 1 , 4 0 4 . 3 9}$ & $\mathbf{\$ 1 4 4 . 2 0}$ \\
\hline $\begin{array}{l}\text { Total Cost of a Client System } \\
\text { (approximately) }\end{array}$ & & & \\
\hline
\end{tabular}

Table 3. Hardware and Software Costs for 2 Servers and 20 Clients [17]-[19]

\begin{tabular}{|l|c|c|c|}
\hline \multicolumn{1}{|c|}{ System } & $\begin{array}{c}\text { Existing System } \\
\text { (HP EliteDesk 800 G1 DM) }\end{array}$ & $\begin{array}{c}\text { Assumed System } \\
\text { (Dell OptiPlex 780) }\end{array}$ & $\begin{array}{c}\text { Proposed System } \\
\text { (Raspberry Pi 2 Model B) }\end{array}$ \\
\hline $\begin{array}{l}\text { Total Cost of 20 Client } \\
\text { Systems (NZ\$) }\end{array}$ & $\$ 51,383.80$ & $\$ 28,087.80$ & $\$ 2,884.00$ \\
\hline $\begin{array}{l}\text { Total Cost of 2 Server } \\
\text { Systems (NZ\$) }\end{array}$ & $\$ 40,266.00$ & $\$ 7,460.00$ & $\$ 7,460.00$ \\
\hline Total Cost (approximately) & $\mathbf{\$ 9 1 , 6 4 9 . 8 0}$ & $\mathbf{\$ 3 5 , 5 4 7 . 8 0}$ & $\mathbf{\$ 1 0 , 3 4 4 . 0 0}$ \\
\hline
\end{tabular}

Table 4. Operational Cost [20]

\begin{tabular}{|l|c|c|c|}
\hline Cost Factors (NZ\$) & $\begin{array}{c}\text { Existing System } \\
\text { (HP EliteDesk 800 G1 DM) }\end{array}$ & $\begin{array}{c}\text { Assumed System } \\
\text { (Dell OptiPlex 780) }\end{array}$ & $\begin{array}{c}\text { Proposed System } \\
\text { (Raspberry Pi 2 Model B) }\end{array}$ \\
\hline $\begin{array}{l}\text { Power Consumption (per year) } \\
\text { Power Consumption of 20 Clients } \\
\text { (8 hours per day) }\end{array}$ & $\$ 990.00$ & $\$ 3740.40$ & $\$ 302.60$ \\
\hline $\begin{array}{l}\text { Power Consumption of 2 Servers } \\
\text { (24 hours per day) }\end{array}$ & $\$ 5,790.00$ & $\$ 5,790.00$ & $\$ 5,790.00$ \\
\hline $\begin{array}{l}\text { Human Resources \& Internet } \\
\text { Connection Fee (per year) }\end{array}$ & & & \\
\hline Staff Payment (2 persons) & $\$ 120,000.00$ & $\$ 120,000.00$ & $\$ 120,000.00$ \\
\hline $\begin{array}{l}\text { Internet Connection Fee } \\
\text { (Fiber 100/50 - Unlimited Data) }\end{array}$ & $\$ 2,028.00$ & $\$ 2,028.00$ & $\$ 2,028.00$ \\
\hline Total Cost (approximately) & $\$ \mathbf{1 2 8 , 8 0 8 . 0 0}$ & $\$ 131, \mathbf{5 8 8 . 4 0}$ & $\$ 128,120.60$ \\
\hline
\end{tabular}


Table 4 displays the total of the calculated operating cost for all systems. This is how much the schools would spend in order to have system administrators maintain the LCC environment. The total of these costs are the total operating costs for that period [21], [22].

Table 5 outlines the total cost for 20 client systems and 2 servers of existing systems, assumed systems and proposed systems. This total amount represents approximate costs associated with human resources, power consumption, hardware and software. For a one-off implementation cost of the Raspberry Pi 2-based LCC system, there is a cost savings of 88.7\% (against Existing System) and 71\% approximately (against the Assumed System); however, the difference in operational cost is not significant across the three system implementations.

Table 5. Total Cost

\begin{tabular}{|c|c|c|c|}
\hline System & $\begin{array}{c}\text { Existing System } \\
\text { (HP EliteDesk } 800 \text { G1 DM) } \\
\end{array}$ & $\begin{array}{c}\text { Assumed System } \\
\text { (Dell OptiPlex 780) } \\
\end{array}$ & $\begin{array}{c}\text { Proposed System } \\
\text { (Raspberry Pi 2 Model B) } \\
\end{array}$ \\
\hline $\begin{array}{l}\text { Total Cost of } 20 \text { Client } \\
\text { Systems (NZ\$) }\end{array}$ & $\$ 51,383.80$ & $\$ 28,087.80$ & $\$ 2,884.00$ \\
\hline $\begin{array}{l}\text { Total Cost of } 2 \text { Server Systems } \\
\text { (NZ\$) }\end{array}$ & $\$ 40,266.00$ & $\$ 7,460.00$ & $\$ 7,460.00$ \\
\hline Operational Cost & $\$ 128,808.00$ & $\$ 131,588.40$ & $\$ 128,120.60$ \\
\hline $\begin{array}{l}\text { Total Cost of the Network } \\
\text { (approximately) }\end{array}$ & $\$ 220,457.80$ & $\$ 167,136.20$ & $\$ 138,464.60$ \\
\hline
\end{tabular}

\section{Discussion}

The purpose of this section is to discuss the results of analysed data from the pilot test of the implemented LCC environment for libraries and classrooms in developing countries.

\subsection{Discussion of Findings from Survey}

Gender and age: Gender and age data were collected while conducting the pilot survey. According to the results, there were $51.4 \%$ females and $48.6 \%$ males participants. Most of the female participants were impressed with the way the system worked and were keen to perform more activities on the Raspberry Pi 2 client computer.

Regarding the analysis of the findings the purpose of using computers in libraries such as web browsing, office applications (for assignments), emails, $35.11 \%$ of the respondents used computers for web browsing whereas $24.47 \%$ used it for checking their emails and $24.47 \%$ of participant used computers for doing assignments (office applications). Only a small percentage of the participants stated that they used computers to listen to music and play games and other personal activities. It is doubtful that the majority of the respondents did not give the correct information in this part of the questionnaire survey.

While conducting the pilot testing and online survey, some participants were very impressed with how the system (LCC systems) worked. Most of the participants taking part in the survey were females. The majority of student participants used computers in the library for several reasons such as checking personal emails, work on academic assessments, researching and surfing the Internet. Only a few stated they do not use the computers in the library.

The results of the survey provided an insight into how the participants used the LibreOffice Suite, file sharing and printing services as well as web browsing on Raspberry Pi 2- based computers. 87\% of participants agreed that the proposed system could be a suitable replacement for computers in the libraries and classrooms in developing countries due to different reasons such as low cost, efficiency, suitable budget. $13 \%$ of participants disagreed because the LCC system appeared too complicated for them. In fact, these participants were already familiar with Microsoft Windows operating systems but the LCC system utilised a 
different operating system (Linux). The majority of the participants suggested that the responsiveness of the Raspberry Pi 2 client system needed to improve. This is attributed to lack of processing power for intensive computing tasks and limited system memory on Raspberry Pi 2 devices. [Note: This pilot testing and survey was conducted in 2015, before the release of Raspberry Pi 3].

\subsection{Limitations}

The survey was limited to selected staff and randomly invited students who had agreed to participate in the survey. The results of the survey do not distinguish between data collected from staff and students, i.e. data not grouped. Since there could be a difference in computing skill levels and computer usage patterns between staff and students, some of the results from survey could be skewed.

\section{Conclusion and Future Work}

In this research, a LCC test-bed environment for school libraries in developing countries was designed and implemented. To answer the research questions, data was collected using an online survey questionnaire after usability testing was performed by each participant. The collected data was analyzed and a CBA was conducted using the existing library computing environment (as a reference), assumed computing environment and proposed LCC environment. After data analysis and CBA were completed, research questions were answered and the benefits of the proposed LCC system were compared with the existing and assumed systems. To sum up, implementing the proposed LCC system could have potential benefits in saving power, human resources, hardware and software costs.

In the future, an Intrusion Detection or Intrusion Prevention system (IDS/IPS such as Security Onion, BroIDS, Snort IDS etc.) and a Virtual Private Network (VPN) solution will be integrated into the LCC system for added security. An additional domain controller will be implemented for redundancy purposes. Similarly, additional network services such Zimbra for enterprise email and cloud storage services such as PiCloud or OwnCloud will be integrated into the LCC environment.

Microsoft Hyper-V service was used on Microsoft Windows Server 2012 R2 for operating system virtualization in the LCC system. This is to be replaced with an open source (no cost) virtualization bundled solution (such as Proxmox VE, Xen, Citrix XenServer or oVirt). Raspberry Pi 2 to be replaced with Raspberry Pi 3, Odroid-C2 or similar alternatives.

\section{Appendix}

\section{Client Software}

Table 6. Client Operating System for LCC System

\begin{tabular}{|l|l|c|l|}
\hline \multicolumn{4}{|l|}{ Client Operating System } \\
\hline Operating System & Version & Open Source & Costs \\
\hline Ubuntu MATE & 15.04 & yes & $\$ 0$ \\
\hline
\end{tabular}

Table 7. Client Software for LCC System

\begin{tabular}{|l|l|l|l|l|}
\hline \multicolumn{6}{|l|}{ Client Software } & Version & Purpose & Open Source & Costs \\
\hline Software Name & 5.0 .3 & Office & yes & $\$ 0$ \\
\hline LibreOffice Suite & 42.0 .2 & Web browser & yes & $\$ 0$ \\
\hline Mozilla Firefox & 45 & Web browser & yes & $\$ 0$ \\
\hline Google Chrome & 2.2 .1 & Video player & yes & $\$ 0$ \\
\hline VideoLAN VLC Media Player & &
\end{tabular}


Client Hardware: Mouse, Keyboard, Monitor, Raspberry Pi 2 Model B (with a 16GB microSDHC for storage). Server Software:

Table 8. Server Operating System for LCC System

\begin{tabular}{|c|c|c|c|}
\hline \multicolumn{4}{|c|}{ Server Operating System } \\
\hline Operating System & Version & Open Source & Costs \\
\hline Ubuntu Linux & 14.04.2 LTS & yes & $\$ 0$ \\
\hline Turnkey Linux & 13.0 & yes & $\$ 0$ \\
\hline
\end{tabular}

Table 9. Server Software for LCC System

\begin{tabular}{|l|l|l|l|l|}
\hline \multicolumn{5}{|l}{ Server Software } \\
\hline Software Name & Version & Purpose & Open Source & Costs \\
\hline ISC DHCPd & 4.2 .4 & DHCP Server & yes & $\$ 0$ \\
\hline BIND & 9.9 .5 & DNS Server & yes & $\$ 0$ \\
\hline Webmin & 1.760 & Server Configuration & yes & $\$ 0$ \\
\hline NTP & $4.2 .6 . p 5$ & NTP (Time) Server & yes & $\$ 0$ \\
\hline PHP OpenLDAP & 1.2 .3 & Domain Controller Server & yes & $\$ 0$ \\
\hline Samba & 4.1 .6 & File Share Server \& Print Server & yes & $\$ 0$ \\
\hline CUPS & 1.7 & Print Server Management & yes & $\$ 0$ \\
\hline MySQL & 5.5 .44 & Database Server & yes & $\$ 0$ \\
\hline Bacula & 5.2 .6 & Backup Server & yes & $\$ 0$ \\
\hline OMD & 1.20 & Network Monitoring Server & yes & $\$ 0$ \\
\hline XAMPP & 5.6 .12 & Web Server & yes & $\$ 0$ \\
\hline
\end{tabular}

Hardware: Mouse, Keyboard, Monitor, Dell PowerEdge R730xd Server.

\section{References}

[1] Lynn, H. (2014). Exploring computing education in rural schools in India. Retrieved from https://www.raspberrypi.org/blog/exploring-computing-education-in-rural-schools-in-india/

[2] Slaven, C. (2015). The raspberry Pi phenomenon: Global education uses. Retrieved from http://students.ecohouseinitiative.org/\%EF\%BF\%BCthe-raspberry-pi-phenomenon-global-education-uses

[3] Severance, C., \& Fontichiaro, K. (2013). Raspberry Pi. North Mankato: Cherry Lake Publishing.

[4] Kothari, C. R. (2013). Research Methodology: Methods and Techniques (3th ed.). India: New Age International Pvt Ltd Publishers.

[5] Agrawal, N., \& Singhal, S. (2015). Smart drip irrigation system using raspberry Pi and arduino. Proceedings of International Conference on Computing, Communication \& Automation (ICCCA) (pp. 928-932).

[6] Danymol, R., Ajitha, T., \& Gandhiraj, R. (2013). Real-time communication system design using RTL-SDR and Raspberry Pi. Proceedings of International Conference on Advanced Computing and Communication Systems (ICACCS) (pp. 1-5). Coimbatore, India: IEEE.

[7] Kyuchukova, D., Hristov, G., Zahariev, P., \& Borisov, S. (2015). A study on the possibility to use Raspberry Pi as a console server for remote access to devices in virtual learning environments. Proceedings of International Conference on Information Technology Based Higher Education and Training (ITHET) (pp. 1-4).

[8] Srinivasan, M., Anand, B., Antony Venus, A., Victor, A., Narayanan, M., Sree Rakshaa, S., \& Vijayaraghavan, V. (2013). GreenEduComp: Low cost green computing system for education in rural India: A scheme for 
sustainable development through education. Proceedings of IEEE Global Humanitarian Technology Conference (GHTC) (pp. 102-107).

[9] Soetedjo, A., Mahmudi, A., Ashari, M., \& Nakhoda, Y. (2014). Raspberry Pi based laser spot detection. Proceedings of International Conference on Electrical Engineering and Computer Science (ICEECS) (pp. 7-11).

[10] Byrne, J., Fisher, L., \& Tangney, B. (2015). Computer science teacher reactions towards raspberry Pi continuing professional development (CPD) workshops using the Bridge21 model. Proceedings of the 10th International Conference on Computer Science \& Education (ICCSE) (pp. 267-272). Cambridge: IEEE.

[11] Fung, P., White, D., Jouet, S., Singer, J., \& Pezaros, D. (2013). The glasgow raspberry Pi cloud: A scale model for cloud computing infrastructures. Proceedings of IEEE 33rd International Conference on Distribute Computing Systems Workshops (ICDCSW) (pp. 108-112). Philadelphia, PA: IEEE.

[12] Kaup, F., Gottschling, P., \& Hausheer, D. (2014). PowerPi: Measuring and modeling the power consumption of the raspberry Pi. Proceedings of IEEE 39th Conference on Local Computer Networks (LCN) (pp. 236-243). Edmonton, AB: IEEE.

[13] McLeod, S. (2012). Experimental Method. Retrieved August 30, 2016, from the website: http://www.simplypsychology.org/experimental-method.html

[14] Tsukada, M., Santa, J., Matsuura, S., Ernst, T., \& Fujikawa, K. (2014). On the experimental evaluation of vehicular networks: Issues, requirements and methodology applied to a real use case. EAI Endorsed Transactions on Industrial Networks and Intelligent Systems.

[15] Wen, K., \& Chang, S. (2014). A study of visualization analysis method in crowd flow spatial survey. Proceedings of the 22nd International Conference on Geoinformatics (pp. 1-7).

[16] Meg, S., \& Mary, M. (2015.). Using Cost Analysis in Evaluation. Retrieved August 30, 2016, from the website: http://ag.arizona.edu/sfcs/cyfernet/cyfar/Costben2.htm

[17] Layard, R., \& Glaister, S. (1994). Cost-Benefit Analysis (2nd ed.). Cambridge, United Kingdom: Cambridge University Press.

[18] Borysowich, C. (2009). CBA sample. Retrieved September 30, 2015, from the website: http://www.scribd.com/doc/20757582/CBA-Sample\#scribd

[19] Mishan, E. J., \& Quah, E. (2007). Cost-Benefit Analysis. Abingdon, Oxford, United Kingdom: Taylor \& Francis.

[20] Markgraf, B., \& Media, D. How to calculate the total operating costs \& breakeven volume. Retrieved from http://smallbusiness.chron.com/calculate-total-operating-costs-breakeven-volume-63129.html

[21] How much does it cost. (2015). Retrieved September 30, 2015, from the website : http://www.powershop.co.nz/how-much-does-it-cost/

[22] Allen, D. (2007). Cost/benefit analysis for implementing ECM, BPM Systems. Information Management Journal, 41(3), 34. Retrieved from http://www.arma.org/bookstore/files/Allen.pdf

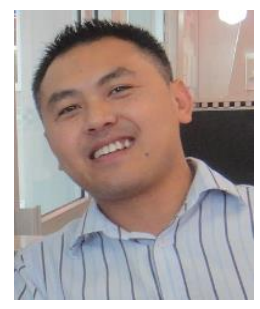

Ar Kar Kyaw is an ICT lecturer at Whitireia Polytechnic's Auckland campus. His research interests include computer security, information security, wireless networks, medical informatics, digital forensics, internet of things (IoT) and cloud computing.

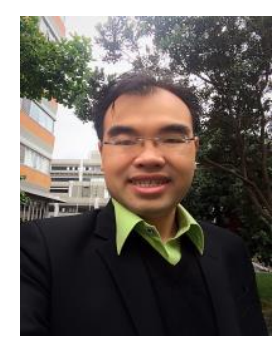

Hong Phat Truong is a system engineer at Super Shuttle, New Zealand. His research interests include computer networks and security. 
Justin Joseph is an ICT lecturer at Whitireia Polytechnic's Auckland campus. His research interests include computer security, wireless sensor networks (WSN), internet of things (IoT) and cloud computing. 